\title{
Effects of constructing a new airport on Ishigaki Island
}

\author{
Y. Maeno ${ }^{1}$, H. Gotoh ${ }^{1}$, M. Takezawa ${ }^{1} \&$ T. Satoh ${ }^{2}$ \\ ${ }^{I}$ Nihon University, Japan \\ ${ }^{2}$ Nihon Harbor Consultants Ltd., Japan
}

\begin{abstract}
Okinawa Prefecture marked the $40^{\text {th }}$ anniversary of its reversion to Japanese sovereignty from US control in 2012. Such isolated islands are almost under the environment separated by the mainland and the sea, so that they have the economic differences from the mainland and some policies for being active isolated islands are taken. It is necessary to promote economical measures in order to increase the prosperity of isolated islands through initiatives involving tourism, fisheries, manufacturing, etc. In this study, Ishigaki Island was considered as an example of such an isolated island. Ishigaki Island is located to the west of the main islands of Okinawa and the second-largest island of the Yaeyama Island group. Ishigaki Island falls under the jurisdiction of Okinawa Prefecture, Japan's southernmost prefecture, which is situated approximately half-way between Kyushu and Taiwan. Both islands belong to the Ryukyu Archipelago, which consists of more than 100 islands extending over an area of $1,000 \mathrm{~km}$ from Kyushu (the southwesternmost of Japan's four main islands) to Taiwan in the south. Located between China and mainland Japan, Ishigaki Island has been culturally influenced by both countries. Much of the island and the surrounding ocean are protected as part of Iriomote-Ishigaki National Park. Ishigaki Airport, built in 1943, is the largest airport in the Yaeyama Island group. The runway and air security facilities were improved in accordance with passenger demand for larger aircraft, and the airport became a tentative jet airport in May 1979. Local consensus has subsequently been reached for the construction of a new airport with a 2,000 m-long runway and plans are currently in the development phase. It is discussed in this paper how the economy of Ishigaki Island will be stimulated by the new Ishigaki airport.
\end{abstract}

Keywords: isolated island, new airport, environment, national park, economy. 


\section{Introduction}

Ishigaki Island $\left(124^{\circ} 9^{\prime \prime} \mathrm{E}, 24^{\circ} 20^{\prime \prime} \mathrm{N}\right)$ is located $460 \mathrm{~km}$ to the southwest of the main Okinawa Islands and is the second-largest island of the Yaeyama Island group. Ishigaki Island, which has a population of approximately 48,000 people and an area of $223 \mathrm{~km}^{2}$, functions as the political, economic, education and transport center of the Yaeyama Archipelago. The island is surrounded by the Pacific Ocean and the East China Sea. The highest point on the island is $526 \mathrm{~m}$ above sea level (ASL) on Mount Omoto. Ishigaki Airport is the largest airport in the Yaeyama island group and Japan's largest third-class airport. The airport was opened in 1943 for military use and converted to a civilian airport in 1956. The runway was extended from $1,200 \mathrm{~m}$ to $1,300 \mathrm{~m}$ in 1968. The New Ishigaki Airport will be opened at another location approximately $10 \mathrm{~km}$ to the northeast of the existing airport in 2014. The runway of the new airport is planned to be 2,000 m-long. Ishigaki Island is blessed with abundant marine resources and natural environments and it is anticipated that the new airport will increase the number of tourists visiting the island in the future. Figure 1 shows the Ryukyu Islands $\left(125^{\circ}-129^{\circ} \mathrm{E}, 24^{\circ}-28^{\circ} \mathrm{N}\right)$ including the Miyako and Yaeyama island groups at the southernmost end of the Japanese Archipelago [1].

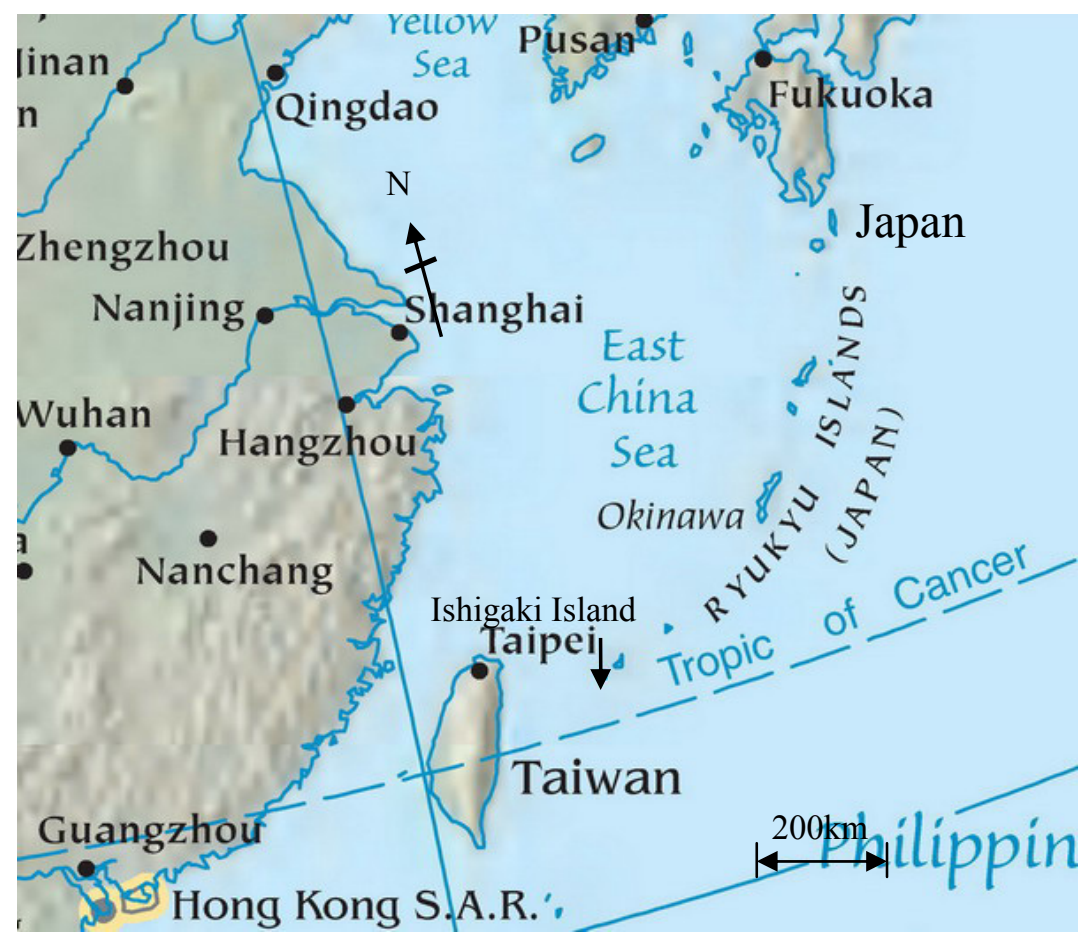

Figure 1: $\quad$ Ryukyu Islands (from Wikipedia, the free encyclopedia). 


\section{Yaeyama Islands}

The Yaeyama Islands are a group of islands in Okinawa Prefecture, Japan. The island group consists of 12 inhabited islands (Ishigaki, Taketomi, Kohama, Kuro, Aragusuku-Kamiji, Aragusuku-Shimoji, Iriomote, Yubu, Hatoma, Hateruma Kayama and Yonaguni) and three uninhabited islands. The administrative district of Ishigaki Island is the Ishigaki City, Yonaguni Town is responsible for Yonaguni Island and Taketomi Town is responsible for the remaining eight islands. Of the 12 islands, Iriomote and Ishigaki islands are larger than $100 \mathrm{~km}^{2}$; Iriomote Island is $289.27 \mathrm{~km}^{2}$ and Ishigaki Island is $222.67 \mathrm{~km}^{2}$. The locations of the Okinawa, the Miyako and Yaeyama island groups within Okinawa Prefecture are shown in Fig. 2. The longitude and the latitude of each Island are as follows: Okinawa Islands $\left(128^{\circ} \mathrm{E}, 27^{\circ} \mathrm{N}\right)$, Miyako Islands $\left(125.5^{\circ} \mathrm{E}, 25^{\circ} \mathrm{N}\right)$, Yaeyama Islands $\left(124^{\circ} \mathrm{E}, 24^{\circ} \mathrm{N}\right)$. The locations of each island in the Yaeyama island group are shown in Fig. 3. Table 1 shows the areas, populations and number of houses of each island in the Yaeyama groups. With their tropical atmosphere and laid back, rural lifestyle, the Yaeyama Islands are a popular getaway destination for those wishing to escape the hustle and bustle of Japan's metropolises. This island paradise offers beaches, snorkeling, diving and relaxation. Of the Yaeyama Islands, Ishigaki Island is the most populated and serves as the region's transportation hub. Other islands include the jungle covered Iriomote Island and Taketomi Island, famous for its beautifully preserved, traditional Ryukyu village. Five additional islands comprise the rest of the island chain and offer beaches, snorkeling and diving [1-3].

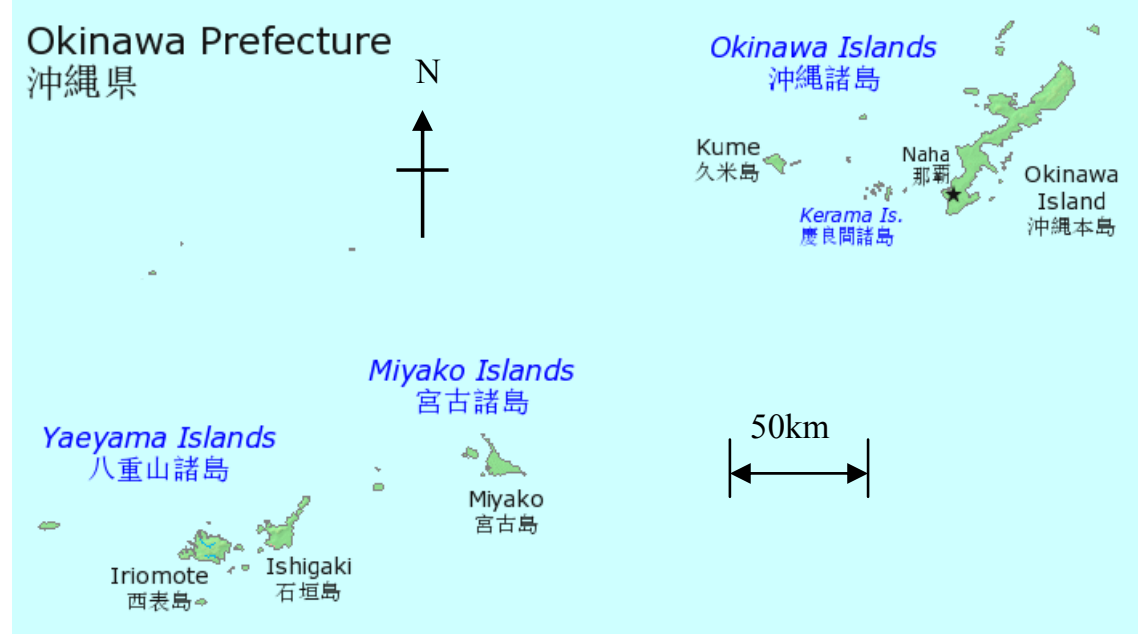

Figure 2: $\quad$ Okinawa Prefecture (from Wikipedia, the free encyclopedia). 
Table 1: Area, population, household and administrative center of each island in Yaeyama Islands [2].

\begin{tabular}{|c|c|c|c|c|}
\hline Island & Area $\left(\mathrm{km}^{2}\right)$ & Population & Household & $\begin{array}{c}\text { Administrative } \\
\text { center }\end{array}$ \\
\hline Ishigaki & 222.63 & 48,089 & 21,410 & Ishigaki City \\
\hline Ko & 0.37 & 0 & 0 & Ishigaki City \\
\hline Taketomi & 5.42 & 313 & 169 & Taketomi Town \\
\hline Iriomote & 289.27 & 2,215 & 1,153 & Taketomi Town \\
\hline Hatoma & 0.96 & 42 & 31 & Taketomi Town \\
\hline Yubu & 0.16 & 20 & 16 & Taketomi Town \\
\hline Kohama & 7.84 & 584 & 326 & Taketomi Town \\
\hline Kuro & 10.02 & 206 & 118 & Taketomi Town \\
\hline $\begin{array}{c}\text { Aragusuku } \\
\text { (Kamiji) }\end{array}$ & 1.76 & 10 & 9 & Taketomi Town \\
\hline $\begin{array}{c}\text { Aragusuku } \\
\text { (Shimoji) }\end{array}$ & 1.58 & 3 & 3 & Taketomi Town \\
\hline Hateruma & 12.77 & 533 & 258 & Taketomi Town \\
\hline Uchibanari & 2.10 & 0 & 0 & Taketomi Town \\
\hline Kayama & 0.39 & 2 & 1 & Taketomi Town \\
\hline Sotobanari & 1.32 & 0 & 0 & Taketomi Town \\
\hline Yonaguni & 28.91 & 1,556 & 766 & Yonaguni Town \\
\hline Total & 585.49 & 53,575 & 24,559 & \\
\hline
\end{tabular}

From Project Bureau, Okinawa Prefecture (2011): Material on isolated islands [2].

Yaeyama Islands 八重山諸島

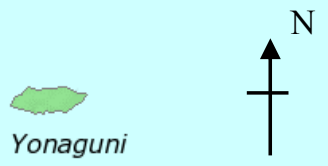

与那国島

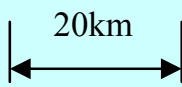

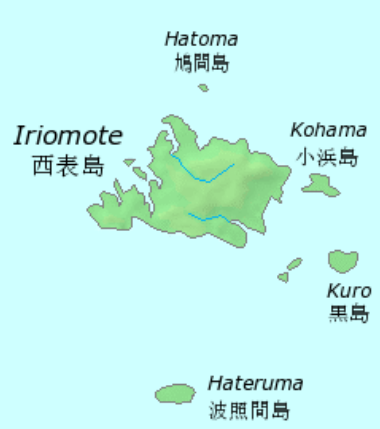

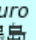

Ishigaki

石垣島

竹富岛

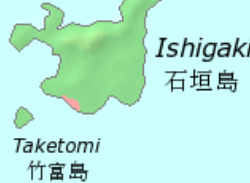

Figure 3: $\quad$ Yaeyama Islands (from Wikipedia, the free encyclopedia). 


\section{Ishigaki and Iriomote Island}

A map of Ishigaki and Iriomote Islands is shown in Fig. 4 [3]. Ishigaki Island is an island west of Okinawa Archipelago and the second-largest island of the Yaeyama Island group. The Ishigaki City in Okinawa Prefecture is the business and transport center of the archipelago. Much of the island and surrounding waters, including Mount Omotodake and Kabira Bay, are protected as part of Iriomote-Ishigaki National Park. The Mount of Omotodake in the center of Ishigaki Island is $526 \mathrm{~m} \mathrm{ASL}$. The northern slopes of the mountain are covered by forest and a coral reef is located to the south of the mountain.

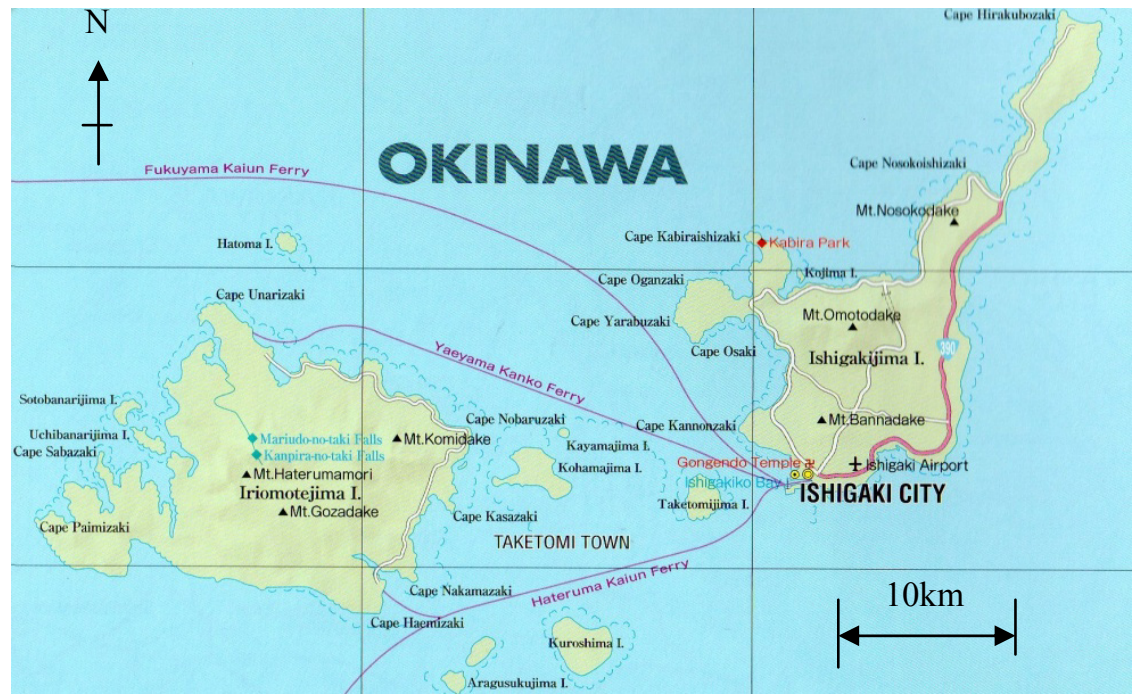

Figure 4: Ishigaki and Iriomote Island (from ATRAS JAPAN of Mapple Press [3]).

Iriomote Island is the largest of the Yaeyama Islands. The total population is less than 2,000, and infrastructure is limited to a single coastal road connecting the hamlets on the northern and eastern shores. The island does not have an airstrip, and most visitors arrive from Ishigaki Island by ferry.

Table 2: Change of population in Ishigaki, Iriomote, Yaeyama Islands and Okinawa Prefecture [2].

\begin{tabular}{|l|r|r|r|r|r|}
\hline Year & \multicolumn{1}{|c|}{1990} & \multicolumn{1}{c|}{1995} & \multicolumn{1}{c|}{2000} & \multicolumn{1}{c|}{2005} & \multicolumn{1}{c|}{2010} \\
\hline Ishigaki & 41,246 & 41,777 & 43,302 & 45183 & 48,089 \\
\hline Iriomote & 1,711 & 1,887 & 1,976 & 2,318 & 2,235 \\
\hline Yaeyama D. & 46,546 & 47,086 & 48,705 & 51,171 & 53,575 \\
\hline Okinawa P. & $1,222,398$ & $1,273,440$ & $1,318,220$ & $1,361,694$ & $1,406,176$ \\
\hline
\end{tabular}


The population of Ishigaki Island, which is increasing on a year-on-year basis (Table 2), is concentrated to the south of the mountain. Table 2 is the changes of population in Ishigaki, Iriomote, Yaeyama Islands and Okinawa Prefecture [2].

The climate of Ishigaki Island is tropical and the vegetation is dominated by tropical forest. Average annual temperature and humidity are approximately $24^{\circ} \mathrm{C}$ and $77 \%$, respectively, and the average annual precipitation is about 2000 $\mathrm{mm}$. Table 3 shows the average temperature (maximum - minimum), the average annual precipitation, the hour of sunlight, the average relative humidity and the average wind velocity from 1971 to 2000 in Ishigaki, Iriomote, Yonaguni, Naha, Kagoshima and Tokyo [4].

Table 3: Comparison with average temperature (maximum - minimum), average annual precipitation, annual hours of sunlight, average humidity and average wind velocity (1971-2000) [4].

\begin{tabular}{|c|c|c|c|c|c|}
\hline & $\begin{array}{c}\text { Average } \\
\text { Temperature } \\
(\text { Max-Min) } \\
\left({ }^{\circ} \mathrm{C}\right)\end{array}$ & $\begin{array}{c}\text { Average } \\
\text { annual } \\
\text { Precipitation } \\
(\mathrm{mm})\end{array}$ & $\begin{array}{c}\text { Hours } \\
\text { of } \\
\text { sunlight } \\
(\text { hour })\end{array}$ & $\begin{array}{c}\text { Average } \\
\text { humidity } \\
(\%)\end{array}$ & $\begin{array}{c}\text { Average } \\
\text { wind } \\
\text { velocity } \\
(\mathrm{m} / \mathrm{s})\end{array}$ \\
\hline Ishigaki & $\begin{array}{c}24.0 \\
(26.6-21.9)\end{array}$ & $2,061.0$ & $1,852.6$ & 77 & 4.7 \\
\hline Iriomote & $\begin{array}{c}23.4 \\
(26.4-20.9)\end{array}$ & $2,342.3$ & $1,536.3$ & 81 & 4.3 \\
\hline Yonaguni & $\begin{array}{c}23.6 \\
(26.0-21.6)\end{array}$ & $2,363.5$ & $1,577.4$ & 78 & 6.5 \\
\hline Naha & $\begin{array}{c}22.7 \\
(25.3-20.5)\end{array}$ & $2,036.9$ & $1,820.9$ & 75 & 5.3 \\
\hline Kagoshima & $\begin{array}{c}18.3 \\
(22.4-14.5)\end{array}$ & $2,279.0$ & $1,918.9$ & 71 & 3.4 \\
\hline Tokyo & $\begin{array}{c}15.9 \\
(19.7-12.5)\end{array}$ & $1,466.7$ & $1,847.2$ & 57 & 3.3 \\
\hline
\end{tabular}

( ):average daily maximum temperature - average daily minimum temperature.

Few forests remain on the island as these have been developed for an extended period. However, there are numerous valuable organisms as Satakentia liukiuensis (Japanese name: Yaeyamayashi) and an endemic palm that has been designated natural monument. In addition, the largest mangrove forest in Japan can be found at the mouth of the Miyara River in Nagura Anparu, which is a registered Ramsar site.

In 2005 , primary industry on Ishigaki Island accounted for $11.2 \%$ of the economy, secondary industry accounted for $15.7 \%$, and tertiary industries accounted for $70.7 \%$. For several decades, the number of people engaged in primary industrial activities on Ishigaki Island and elsewhere on the Ryukyu archipelago has been decreasing, while the number of workers in tertiary industrial activities has been increasing. This decrease in the primary industrial sector is considered to be due to advancing the elimination of labor in the 
enlargement of management area and an increase in mechanization. In addition, the widening gaps for the other industry and the marked increase in the number of visitors have drained jobs away from the primary industries to the tertiary industries. The changes of visitors in Ishigaku, Taketomi, Iriomote Islands is shown in Table 4 in 1975, 1985, 1995 and 2008 [2].

Table 4: $\quad$ Changes of visitors in 1975-2008 (unit: persons).

\begin{tabular}{|c|r|r|r|r|}
\hline Island & 1975 & 1985 & 1995 & 2008 \\
\hline Ishigaki & 79,000 & 250,072 & 446,830 & 771,106 \\
\hline Taketomi & 52,784 & 80,880 & 109,269 & 445,100 \\
\hline Iriomote & 42,125 & 71,405 & 201,967 & 384,900 \\
\hline Yaeyama D. & 205,438 & 475,536 & 864,762 & $1,902,635$ \\
\hline
\end{tabular}

The first Regional Disaster Prevention Plan of Ishigaki City was formulated by the Local Disaster Management Council of Ishigaki City in 1986. Afterwards the plan was revised in 1993, 1998 and 2012. Estimation of disaster in relation to typhoon, earthquake and tsunami based on the past cases was taken in this plan.

Ishigaki Island is frequently struck by typhoons. The dead or the missing were 4 people in 1977 (Typhoon Bella), and the seriously or slightly injured were 57 people in 2006 (Typhoon Shanshan). 227 houses were completely or partially destroyed by Typhoon Bella and 157 houses were completely or partially destroyed by Typhoon Shanshan. Typhoon disaster in Ishigaki Island is estimated by these 2 typhoons. Earthquake and Tsunami disaster in Ishigaki Island is estimated by the Ishigakijima eastward offshore earthquake and the Ishigakijima southward offshore earthquake. Ishigaki Island was hit by a 40 to $80 \mathrm{~m}$ high tsunami in 1771 and about 8,500 people were killed by the tsunami. It is estimated in the report of earthquake disaster estimation in Okinawa Prefecture that about 1,500 houses will be completely or partially destroyed and number of dead, missing and seriously or slightly injured will be about 1,200 people by the Ishigakijima eastward offshore earthquake and Ishigakijima southward offshore earthquake. And also, it is estimated in the report that about 1,800 houses will be completely or partially destroyed and about 6,000 people will be killed or injured by tsunami of the Ishigakijima eastward earthquake and the Ishigakijima southward offshore earthquake. The Regional Disaster Prevention Plan of Ishigaki City revised in 2012 is the disaster plan formulated in regulating of the Basic Act on Disaster Control Measures (Japanese Government enacted in 1961) by the Local Disaster Management Council of Ishigaki City. The disaster plan provides the disaster prevention plan, the disaster first-aid measures plan, the disaster recovery and reconstruction plan for storm and flood damages, earthquake, and tsunami. The Communication, Education and Public Awareness for making these plans known to every citizens is always endeavored by map exercises and practical trainings on coordinating and cooperating among Ishigaki City and the organizations. 


\section{New Ishigaki Island Airport}

The existing Ishigaki Airport was opened in 1943 for military use, and then converted to a civilian airport in 1956. The runway was extended from 1,200 m to $1,500 \mathrm{~m}$ in 1968 as being stated above. Ishigaki Airport is situated $1.9 \mathrm{~km}$ from the center of Ishigaki Island in Okinawa Prefecture, Japan. The existing airport essentially serves as the hub of the Yaeyama Zone and conducts flights to major cities on the Japanese mainland (Tokyo, Osaka, Nagoya, Kobe, Fukuoka) as well as Naha, Hateruma and Yonaguni in Okinawa Prefecture. The change in the numbers of passengers and freight handled by Ishigaki Airport is shown in Table 5 [2]. The departures from Ishigaki Airport don't contain the freight via Naha Airport (for examples, Ishigaki - Tokyo, Kansai, Kobe, Itami, Nagoya, Fukuoka, Hateruma and Yonaguni) in Table 5. Numbers of passengers and freights have remained at the same level or the tendency to decrease for the past few years. However, demand forecasting values of New Ishigaki Airport in 2021 are expected to reach at about 2,597,000 passengers and 13,736 freight tonnages per year [5].

Table 5: Changes in the number of passengers and freight handled by Ishigaki Airport: upper: passenger (person) lower: freight (ton).

\begin{tabular}{|l|c|r|r|r|r|}
\hline Route & Distance & \multicolumn{1}{|c|}{2006 year } & 2007year & \multicolumn{1}{c|}{ 2008year } & \multicolumn{1}{c|}{ 2009year } \\
\hline Ishigaki - & $2,171 \mathrm{~km}$ & 163,514 & 148,400 & 143,443 & 133,855 \\
Tokyo & & 831,646 & 874,470 & 706,968 & 791,961 \\
\hline Ishigaki & $1,650 \mathrm{~km}$ & 128,598 & 92,845 & 80,430 & 75,956 \\
- Kansai & & 443,789 & 709,190 & 744,341 & 551,911 \\
\hline Ishigaki - & $1,680 \mathrm{~km}$ & - & 65,192 & 82,983 & 75,970 \\
Kobe & & - & 51,888 & 224,603 & 263,098 \\
\hline Ishigaki - & $1,709 \mathrm{~km}$ & 96,057 & - & - & - \\
Itami & & 550,029 & - & - & - \\
\hline Ishigaki - & $1,865 \mathrm{~km}$ & 39,961 & - & 14,907 & 59,218 \\
Nagoya & & 94,218 & - & 22,791 & 221,128 \\
\hline Ishigaki - & $1,307 \mathrm{~km}$ & 41,872 & - & - & 41,796 \\
Fukuoka & & 113,700 & - & - & 9,400 \\
\hline Naha- & $472 \mathrm{~km}$ & $1,358,124$ & $1,438,703$ & $1,408,132$ & $1,199,228$ \\
Ishigaki & & $9,399,357$ & $8,671,799$ & $13,238,476$ & $10,297,859$ \\
\hline Miyako - & $183 \mathrm{~km}$ & 104,606 & 88,552 & 73,869 & 63,132 \\
Ishigaki & & 315,530 & 162,963 & 177,522 & 184,467 \\
\hline Ishigaki- & $63 \mathrm{~km}$ & 4,701 & 2,984 & - & - \\
Hateruma & & 7,194 & 3,472 & - & - \\
\hline Ishigaki - & $175 \mathrm{~km}$ & 71,943 & 67,606 & 68,438 & 63,724 \\
Yonaguni & & 322,969 & 312,330 & 608,409 & 114,747 \\
& & & & & \\
\hline Total & & $2,009,376$ & $1,904,282$ & $1,872,202$ & $1,712,879$ \\
& & $12,078,432$ & $10,786,112$ & $15,723,110$ & $12,434,571$ \\
\hline
\end{tabular}


It is expected that the number of passengers and the volume of airfreight handled by the airport will increase. However, at present, the transport of passengers and freight by airplane is dependent on the weather, and container transportation is complicated by the short, 1,500-m runway. Since it unlikely that approval from local inhabitants to extend the runway of the existing airport to $2000 \mathrm{~m}$, the existing Ishigaki Airport is serving as a temporary jet airport under an agreement with local inhabitants. However, a new site is being sought as the urban area near the existing airport is increasing and aircraft noise currently exceeds environmental standards. Consequently, in 1999, the construction of a new Ishigaki Airport was proposed by a committee established to find a new location for the new Ishigaki Airport, and an allocation has unofficially been made in the budget of the Japanese government for the new Ishigaki Airport at a new site about $15 \mathrm{~km}$ from the city of Ishigaki as shown in Fig. 5.

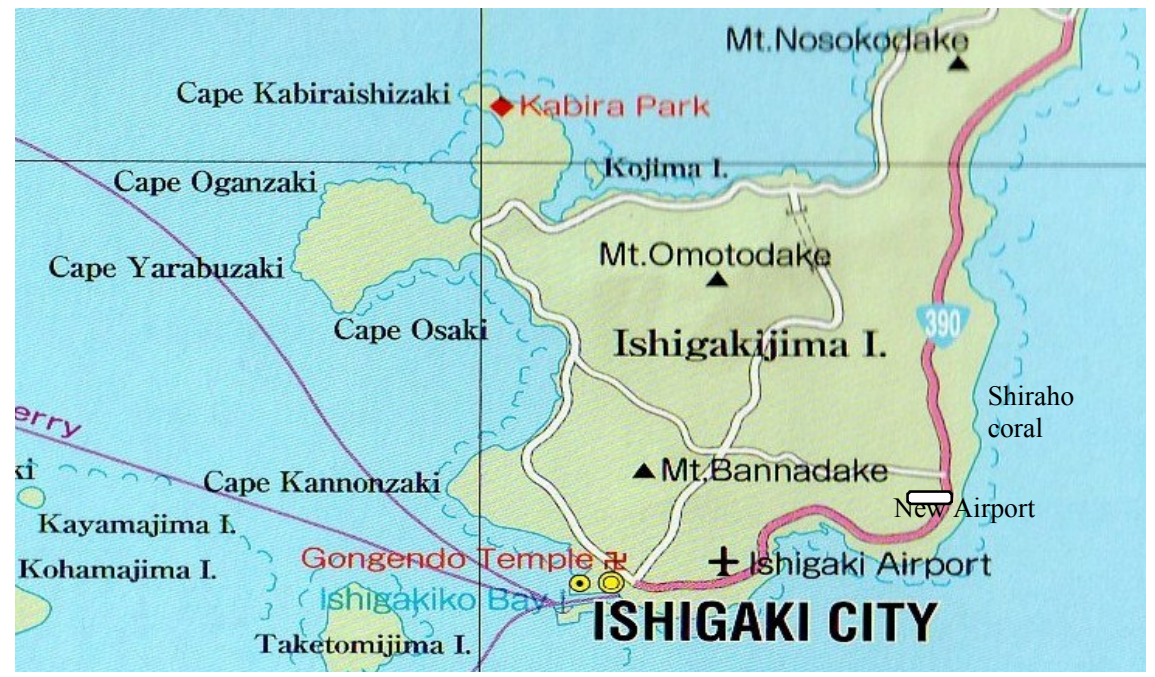

Figure 5: $\quad$ Sites of existing Ishigaki Airport and new Ishigaki Airport. (From ATRAS JAPAN of Mapple Press [3].)

It is considered that approximately $90 \%$ of the inhabitants of Ishigaki and the towns of Taketomi and Yonaguni will be involved in the construction of the New Ishigaki Airport. Approximately $80 \%$ of local inhabitants agree with the site inhabitants are concerned about issues such as nature and soil conservation that would be associated with the airport. In future, it will be expected by inhabitants of islands that the industry is developed by the increase of freight and the economy is has been picked up by the increase of tourists. With a 2,000-m runway, the new Ishigaki Airport will be capable of servicing mid-sized jet airplanes. The new airport will be constructed $31 \mathrm{~m}$ ASL, which is considered to be sufficiently high for protection from tsunamis or tidal waves. The 
construction site is near the Shiraho coral reef, which is about $10 \mathrm{~km}$ long and 1 $\mathrm{km}$ wide [6].

Initial plans for the New Ishigaki Airport made in 1979 were to construct the airport on landfill of the Shiraho coral reef, but the plan was canceled in 1989 due to the drastic opposition by environmentalists of outsider. After several alternate proposals, it was finally decided to construct the New Ishigaki Airport on land in the vicinity of Karadake Mountain in northern Shiraho. The new plan involves the construction of a containment dam to prevent the runoff of red clay from entering the sea. The New Ishigaki Airport is due to be opened in 2014. It is estimated that, after 50 years, the cost-benefit effect of the New Ishikari Airport will be 1.7. This can be calculated by adding the profits derived from users of the airport (492 billion yen) to those from suppliers (132 billion yen), and dividing it by the cost of construction, site acquisition and maintenance, improvements, etc. ( 374 billion yen) and is shown in the relation : $(492+132)$ $1374=1.7$.

The environmental preservation measure is a challenge of New Ishigaki Airport. Various plants and animals of natural monument inhabit and grow in the neighboring area of New Ishigaki Airport. And the coral reef is spreading in the neighboring waters of New Ishigaki Airport. The environmental examination committee, the construction method examination committee and the examination committee of small bat kinds composed by literates, nature conservation groups, etc. were constituted for the environmental impact assessment, so that the environmental preservation measures of monitoring, evasion, reduction, etc. were planned and executed by the guidance and advice of those experts [7].

\section{Conclusions}

The 1972 reversion of Okinawa to Japan came with a price - the continued use by the United States of sprawling military bases and other facilities in the prefecture to protect Japan and maintain peace in the Asia-Pacific region [8].

The Yaeyama island chain, including Ishigaki Island in Okinawa Prefecture, is blessed with abundant natural resources, good weather, agricultural products, and marine products. It is considered that the tourist and travel industries will increase as more people become aware of the diversity of natural environments, as well as the many sites of historical, cultural and geographic interest in southwestern Japan. Ishigaki Island is the main island of the Yaeyama Islands and serves the region's transportation hub. Ishigaki City is the Yaeyama's only urban center and is the site of the region's major airport and boat terminal. The construction of the New Ishigaki Airport is expected to have a beneficial effect on the economy and development of Ishigaki Island and the surrounding islands.

\section{References}

[1] Wikipedia, The free encyclopedia, Yaeyama Islands, http://en.wikipedia.org/wiki/Yaeyama-Islands, 2012.

[2] Project Bureau, Okinawa Prefecture: Material on isolated islands, 2011. 
[3] Mapple, ATRAS JAPAN, Shobun Co. Ltd, 2010.

[4] Yaeyama Branch Office, Okinawa Prefecture: Manual Yaeyama, 2009.

[5] Okinawa Prefecture, Transport performance and demand forecast in the New Ishigaki Airport, http://www.pref.okonawa.jp/shin-ishigaki /yusoujituseki.html, 2012.

[6] New Ishigaki Airport Division, On the New Ishigaki Airport,http://www.pref.0kinawa.jp/shin-ishigaki/newishigaki/index.html, 2012.

[7] Cabinet Office of Japanese Government, Maintenance of New Ishigaki Airport, http://www8.cao.go.jp/okinawa/5/57.html, 2012.

[8] The Japan Times, Okinawa still at forefront of defense plans, May 16, 2012. 